\title{
Article
}

\section{Cerebral oxidative stress and microvasculature defects in TNF-a expressing transgenic and Porphyromonas gingivalis-infected ApoE-/- mice}

Rokad, Farheen, Moseley, Ryan, Hardy, Rowan S, Chukkapalli, Sasanka, Crean, Stjohn, Kesavalu, Lakshmyya and Singhrao, Simarjit Kaur

Available at http://clok.uclan.ac.uk/18764/

Rokad, Farheen, Moseley, Ryan, Hardy, Rowan S, Chukkapalli, Sasanka, Crean, Stjohn ORCID: 0000-0001-9336-8549, Kesavalu, Lakshmyya and Singhrao, Simarjit Kaur ORCID: 0000-0001-9573-5963 (2017) Cerebral oxidative stress and microvasculature defects in TNF- $\alpha$ expressing transgenic and Porphyromonas gingivalis-infected ApoE-/- mice. Journal of Alzheimer's Disease, 60 (2). pp. 359-369. ISSN 1387-2877

It is advisable to refer to the publisher's version if you intend to cite from the work. http://dx.doi.org/10.3233/jad-170304

For more information about UCLan's research in this area go to http://www.uclan.ac.uk/researchgroups/ and search for <name of research Group>.

For information about Research generally at UCLan please go to http://www.uclan.ac.uk/research/

All outputs in CLoK are protected by Intellectual Property Rights law, including Copyright law. Copyright, IPR and Moral Rights for the works on this site are retained by the individual authors and/or other copyright owners. Terms and conditions for use of this material are defined in the policies page. 
Title: Cerebral oxidative stress and microvasculature defects in TNF- $\alpha$ expressing transgenic and Porphyromonas gingivalis-infected $\mathrm{ApoE}^{-/-}$mice

Authors: Farheen Rokad ${ }^{1}$, Ryan Moseley ${ }^{2}$, Rowan S. Hardy ${ }^{3}$, Sasanka Chukkapalli ${ }^{4}$, StJohn Crean ${ }^{1}$, Lakshmyya Kesavalu ${ }^{4,5}$, Sim K. Singhrao ${ }^{1^{*}}$

${ }^{1}$ Dementia \& Neurodegenerative Diseases Research Group, Faculty of Clinical and Biomedical Sciences, School of Dentistry, University of Central Lancashire, UK.

${ }^{2}$ Stem Cells, Wound Repair and Regeneration, School of Dentistry, Cardiff University, UK.

${ }^{3}$ Institute of Metabolism and Systems Research, University of Birmingham, UK.

${ }^{4}$ Department of Periodontology, College of Dentistry, University of Florida, USA.

${ }^{5}$ Department of Oral Biology, College of Dentistry, University of Florida, USA.

Running Title: Hippocampal microvessel protein oxidation

\section{*Corresponding author:}

Dr SK Singhrao.

Tel: $+44(0) 1772895137$.

E-mail: SKSinghrao@uclan.ac.uk 


\begin{abstract}
The polymicrobial dysbiotic subgingival biofilm microbes associated with periodontal disease appear to contribute to developing pathologies in distal body sites, including the brain. This study examined oxidative stress, in the form of increased protein carbonylation and oxidative protein damage, in the tumour necrosis factor- $\alpha(\mathrm{TNF}-\alpha)$ transgenic mouse that models inflammatory TNF- $\alpha$ excess during bacterial infection; and in the apolipoprotein knockout $\left(\mathrm{ApoE}^{--}\right.$) mouse brains, following Porphyromonas gingivalis gingival monoinfection. Following 2,4-dinitrophenylhydrazine derivatization, carbonyl groups were detected in frontal lobe brain tissue lysates by immunoblotting and immunohistochemical analysis of fixed tissue sections from the frontotemporal lobe and the hippocampus. Immunoblot analysis confirmed the presence of variable carbonyl content and oxidative protein damage in all lysates, with TNF- $\alpha$ transgenic blots exhibiting increased protein carbonyl content, with consistently prominent bands at $25 \mathrm{kDa}(\mathrm{p}=0.0001), 43$ $\mathrm{kDa}$ and $68 \mathrm{kDa}$, over wild-type mice. Compared to sham-infected ApoE ${ }^{-/-}$mouse blots, P. gingivalisinfected brain tissue blots demonstrated the greatest detectable protein carbonyl content overall, with numerous prominent bands at $25 \mathrm{kDa}(\mathrm{p}=0.001)$ and $43 \mathrm{kDa}(\mathrm{p}=0.0001)$ and an exclusive band to this group between $30-43 \mathrm{kDa} *(\mathrm{p}=0.0001)$. In addition, marked immunostaining was detected exclusively in the microvasculature in $P$. gingivalis-infected hippocampal tissue sections, compared to sham-infected, wild-type and TNF- $\alpha$ transgenic mice. This study revealed that the hippocampal microvascular structure of P. gingivalis-infected $\mathrm{ApoE}^{-/-}$mice possesses elevated oxidative stress levels, resulting in the associated tight junction proteins being susceptible to increased oxidative/proteolytic degradation, leading to a loss of functional integrity.
\end{abstract}

Keywords: Hippocampus, infection, microvasculature, oxidative stress/damage, Porphyromonas gingivalis, tight junction proteins. 


\section{Introduction}

Oxidative stress is implicated in the onset, progression and pathogenesis of numerous diseases and conditions, including periodontal disease, neurodegeneration and ageing [1-8]. Prolonged episodes of oxidative stress produces an excessive accumulation of reactive oxygen species (ROS), capable of inducing deleterious cellular and biomolecular damage to the host [1-5]. Neurons are particularly sensitive to ROSmediated, oxidative damage, as they contain higher numbers of mitochondria along their cell bodies and axonal/dendritic tree lengths, compared to other cell types. The ROS-mediated oxidiative damage within the brain can potentially lead to neuronal dysfunction, with a likely outcome of Alzheimer's disease (AD) pathology $[3,6,8,9]$. In the ageing brain and during AD, the APOE4 genetic susceptibility further capable of increasing the possibility of recurrent infections, leakage of plasma proteins, ROS and metallic ion production (iron from erythrocyte death), adding to a growing pool of oxidative stress mediators within the brain. Furthermore, oral and extra-oral bacteria are documented to be present within AD brains [10], where these are likely to promote additional ROS generation and host tissue damage. During chronic periodontal infection, oral pathobionts, such as Porphyromonas gingivalis ( $P$. gingivalis), drive the host's immunoinflammatory responses towards elevated levels of pro-inflammatory cytokines, such as tumour necrosis factor- $\alpha$ (TNF- $\alpha$ ), interleukin (IL) IL-1 $\beta$ and IL-6; leading to elevated oxidative stress [11]. This is particularly achieved by the interplay between the phagocytic oxidative burst of the host's neutrophils and macrophages, coupled with the oxidative stress response intiated by bacteria [12]. Furthermore, live $P$. gingivalis infection is likely to exert its effect on the host through a diverse range of virulence factors. Apart from its lipopolysaccharide (LPS), which can cause the host to respond through oxidative burst and other mechanisms, proteolytic activity mediated by $P$. ginivalis gingipains are capable of targetting cell-cell adhesion molecules $[13,14,15]$. It is, therefore, likely that gingipains also contribute to the degradation of endothelial cell tight junction proteins and the subsequent loss of blood-brain barrier (BBB) functional integrity. Oxidative stress from host response also appears to affect a multitude of other activities relevant to $\mathrm{AD}$, including activation of positive feedback between the $\gamma$ - and $\beta$-secretase cleavage of the amyloid- $\beta$ protein precursor $(\mathrm{A} \beta \mathrm{PP})$ metabolic product, amyloid- $\beta(\mathrm{A} \beta)[16]$; and the formation of the inflammasome 
assembly which has subsequent effects on the liberation of mature forms of IL-1ß/IL-18 family members $[17,18]$. These cytokines modulate innate immune responses against microbes by generating a subsequent inflammatory response serving important biological and physiological functions. Inappropriate secretion of cytokines result in pro-oxidant mechanisms especially in neuroinflammatory pathologies. For example, TNF- $\alpha$ has been shown to permeabilise brain microvascular endothelial cells and degrade cell-cell adhesion proteins, such as occludin [19]; and it can induce ROS production in cultured cells [20].

Since neurodegenerative diseases are of complex etiologies, often exhibiting mixed pathologies, the contribution of specific genes is best investgated using animal models. The genetically modified apolipoprotein $\mathrm{E}$ knockout $\left(\mathrm{ApoE}^{-/-}\right)$mouse is a good example, in order to determine the effects of peripheral infection on a host undergoing high intrinsic stress, due to the constitutive expression of the proinflammatory cytokine, TNF- $\alpha$ [21, 22], lipid peroxidation [23], impaired immuno-modulatory function in macrophages and innate/adaptive immune responses [24-26]; and impaired cerebellar microvessels [27-30]. The TNF- $\alpha$ transgenic mouse represents an additional model in which to explore the direct roles of the proinflammatory cytokine, TNF- $\alpha$, in the process of local oxidative stress within the brain. In response to chronic bacterial infection, $\mathrm{TNF}-\alpha$ release represents a proinflammatory cytokine at the apex of the inflammatory cascade that mediates local inflammatory damage including the production of locallized oxidative stress and has been shown to be upregulated in response to $P$. gingivalis LPS in vivo [13-15]. In the TNF- $\alpha$ trangenic mouse, TNF- $\alpha$ mRNA is stabilized and its expression appears to be increased within all tissues, including the brain. This makes the TNF- $\alpha$ trangenic mouse an execellent control model to explore mechanistic insights into how bacterial models of oxidative stress may be mediating their actions [31].

Whilst the cerebral microvessels in TNF- $\alpha$ transgenic and $\mathrm{ApoE}^{-/-}$mice appear to be resilient to tissue damage, the cerebellar $\mathrm{BBB}$ in both these mouse models was leaky when tested for mouse $\operatorname{IgG}$ at the beginning of the investigation. In addition, the cerebral $\mathrm{BBB}$ in $\mathrm{ApoE}^{-/-}$mice have been shown to become leaky either due to experimentally induced physical injury [28], or as recently reported, inflammationmediated physical injury following infection with P. gingivalis [32]. Indeed, this study, demonstrated that both TNF- $\alpha$ expressing transgenic mice and $\mathrm{ApoE}^{-/-}$mice share such leaky cerebellar $\mathrm{BBB}$ characteristics, 
thereby providing a unique opportunity to draw systematic comparions between common biological and physiological factors involved in stress initiation.

We have previously reported associations between $P$. gingivalis LPS and AD brains [33] and subsequently established that $P$. gingivalis is capable of accessing $\mathrm{ApoE}^{-/-}$mouse brains from its primary gingival location $[32,34]$. Once in the brain, $P$. gingivalis modulates innate immune responses via activation of the complement cascade, resulting in bystander injury of functional pyramidal neurons in the hippocampus, following 24 week of chronic infection [34]. A recent investigation using the same ApoE ${ }^{-/-} P$. gingivalis-infected mice brains (24 weeks) provided evidence of BBB defects, with numerous age-related granules and cerebral tissue damage mediated via gingipains [32]. This led us to the rationale that acute phase inflammation, in the form of oxidative stress, may precede loss of the BBB integrity in these mice at an earlier timepoint of infection which was absent in $\mathrm{ApoE}^{-/-} P$. gingivalis-infected mice brains (24 weeks). Therefore, this study sought to critically examine how $P$. gingivalis infection (at 12 weeks) alters acute innate immune responses by increasing oxidative exposure on cerebral parenchyma; and whether this alteration can potentially lead to tissue injury and subsequent hippocampal BBB permeability which was clearly evident at 24 week infection [32].

\section{Materials and Methods}

\section{Negative and positive control mice}

C57BL/6 Tg197 (TNF- $\alpha$ ) transgenic mice were obtained from Dr. George Kollias (BSRC Fleming, Athens, Greece) [31]. At 6-8 weeks, heterozygous TNF- $\alpha$ transgenic mice develop clinical signs of systemic chronic inflammation, mediated due to overexpression of TNF- $\alpha$. Mice were housed under controlled environmental conditions $\left(20.2 \pm 2^{\circ} \mathrm{C}, 14: 10 \mathrm{~h}\right.$ light:dark cycle). Experiments were performed following strict guidelines governed by the UK Animal (Scientific Procedures) Act 1986 and approved (under the Home Office Licence Number granted to the study, 70/8582) by Birmingham Ethical Review Sub Committee. At ten weeks of age, wild type and TNF- $\alpha$ transgenic ( $N=7$ per group) animals were euthanatized by the humane killing of mice under Schedule 1 Code of Practice under UK Home Office Licence conditions; and the brain 
tissues were removed. One hemisphere of the brain was frozen and the other half embedded in paraffin wax blocks. All speicmens (frozen and paraffin wax blocks) were sent to the University of Central Lancashire, UK, for laboratory analysis following approval (RE/15/04/SS) by their Ethical Review Committee.

\section{P. gingivalis infection mouse model}

$\mathrm{ApoE}^{-/-}$male mice (strain B6.129P2-Apoe ${ }^{\mathrm{tm} 1 \mathrm{Unc} / \mathrm{J}}, N=12$ ) were sham-infected or monoinfected for 12 weeks via the oral route, with the $P$. gingivalis FDC 381 strain $\left(5 \times 10^{9}\right.$ bacteria / $\left.\mathrm{mL}\right)$, as described previously [35]. All experimental procedures were conducted in accordance with the guidelines of the University of Florida Institutional Animal Care and Use Committee (IACUC, Protocol \#201304539). All ApoE ${ }^{-/-}$mice brain specimens were collected, stored and shipped to the University of Central Lancashire, UK, for laboratory analysis, following original approval (RE/12/04) and renewed approval (RE/15/04/SS) by their Ethical Review Committee.

\section{Biochemistry}

\section{Brain tissue lysates}

Unfixed brain tissue (approximately $30 \mathrm{mg} /$ mice) from a section of the frontal lobe of each mouse strain (wild-type and TNF- $\alpha$ transgenic mouse groups, $N=7$; sham- and $P$. gingivalis-infected (12 week group, $N$ = 9), was taken and minced in lysis buffer (50 mM Tris buffer, $\mathrm{pH}$ 8.0, $1 \%$ NP40, $150 \mathrm{mM}$ sodium chloride and $5 \mathrm{mM}$ EDTA), containing protease inhibitors (cOmplete ${ }^{\mathrm{TM}}$ ULTRA Tablets, Roche, USA) as per manufacturer's instructions. Following incubation on ice for $20 \mathrm{~min}$ and vortex mixing at regular intervals, the tissue homogenates were centrifuged and supernatants collected [33]. Coomassie Blue Protein Assay (Sigma-Aldrich, UK) determined total protein concentration of each lysate; and samples stored at $-20^{\circ} \mathrm{C}$, until required. 


\section{Western blot analysis of brain tissue lysate protein carbonyl content}

Fresh frontal brain tissue lysates were subjected to derivatization with 2,4-dinitrophenylhydrazine (2,4DNPH) and subsequent Western blot analysis, using an Oxyblot Protein Oxidation Detection Kit (Millipore UK Ltd, UK), according to manufacturer's instructions. Derivatised samples (5 $\mu \mathrm{g}$ protein/well) were separated by SDS-PAGE on $12 \%$ linear gels and electroblotted onto polyvinylidine difluoride (PVDF) membranes, as previously described [36]; and protein carbonyl-containing proteins were detected, as described in the Oxyblot Detection Kit. Chemiluminescent substrate (SuperSignal ${ }^{\circledR}$ West Pico, ThermoFisher Scientific, UK) was prepared and applied to the membranes according to manufacturer's instructions. Specific protein signal from the membranes was visualized using a ChemicDoc ${ }^{\circledR}$ (Bio-Rad, UK) and imges captured with Image Lab ${ }^{\circledR}$ Software Version 3.0.1. The amount of protein loaded/lane was determined by staining the membranes with India ink. Density of the bands of interest was quantified by first importing the blot images into ImageJ and then selecting each band for its total density value using the densitometric program in ImageJ Software (https://imagej.nih.gov/ij/download.html, version 64-bit Java 1.8.0_112). Comparisons were made between raw vlaues of intensities/lane normalized to loading control bands.

\section{Tissue sectioning}

Formalin fixed, paraffin wax-embedded, tissue blocks from the cerebellum and the frontotemporal lobe, inclusive of the hippocampus, were sectioned ( $5 \mu \mathrm{m}$ thickness) using the Leica RM2235 Microtome. Sections were collected on adhesive coated glass microscope slides.

\section{Immunohistochemistry}

\section{Analysis of brain tissue section protein carbonyl content}

Brain tissue sections from wild-type and TNF- $\alpha$ transgenic mice $(N=7)$; and the sham-infected and $P$. gingivalis-infected mice $(N=12)$, were analysed. Sections were deparaffinized, rehydrated and derivitized with 2,4-DNPH, as previously described [37]. All sections were blocked for non-specific binding with $3 \%$ 
normal horse serum and immunostaining performed by overnight incubation with anti-dinitrophenyl (antiDNP) antibody (rabbit whole antisera, Sigma-Aldrich; diluted 1/1200). The study employed three different types of negative controls, whereby (1) 2,4-DNPH derivatization was omitted, (2) free carbonyl groups were reduced with $25 \mathrm{mM}$ sodium borohydride in $80 \%$ methanol, at room temperature for 30 min, before 2,4DNPH derivatization and (3) where the primary antibody was omitted. Immunoreactivity was visualized using the Vectastain Universal Elite ABC Kit and the DAB Peroxidase Kit (both from Vector Laboratories, UK), as per manufacturer's instructions. Following a light haematoxylin based nuclear counterstain, all sections were examined using the Nikon Eclipse E200 Microscope. Images of representative tissue sites were recorded using Nikon DS-L2 v.441 Software.

\section{Statistical analysis}

Data is presented as mean \pm standard deviation $(\mathrm{SD})(\mathrm{N} \geq 3$ replicates per treatment). The data is presented as non-parametric, Mann-Whitney U test for two independent samples using the SPSS version 23 software package to compare wild-type with TNF- $\alpha$ transgenic; and sham-infected with $P$. gingivalis-infected mice. Differences were considered significant at $\mathrm{p} \leq 0.05$.

\section{Results}

\section{Western blot analysis}

Western blot analysis from tissue lysates from a section of the frontal lobe of all the mice tested, confirmed the presence of carbonyl content and oxidative protein damage, at variable molecular weights in the range of 25-70 kDa. Wild-type mouse brain tissue blots (Fig. 1a) consistently exhibited a prominent band around 43 $\mathrm{kDa}$ (Fig. 1a, broken arrow), with additional lesser bands of variable intensities at 25-40 kDa and 45-70 kDa positions. The TNF- $\alpha$ transgenic mouse brain blots (Fig. 1b), exhibited prominent bands at around $25 \mathrm{kDa}$ (Fig. 1b, short arrow), $43 \mathrm{kDa}$ (Fig 1b, broken arrow) and $68 \mathrm{kDa}$ (Fig. 1b, arrow head); and lesser intensity bands at 50-65 kDa. Sham-infected mouse brain blots (Fig. 1c), demonstrated a prominent band at around 25 $\mathrm{kDa}$ (Fig. 1c, short arrow), with additional bands of highly variable degrees of intensities between 29-40 
$\mathrm{kDa}$ and 45-70 kDa. P. gingivalis-infected mouse brain blots (Fig. 1d), exhibited numerous prominent bands at around $25 \mathrm{kDa}$ (Fig 1d, short arrow), and $43 \mathrm{kDa}$ (Fig. 1d, broken arrow); and one exclusive to this group between 30-43 kDa* (Fig. 1d, astrix), with lesser bands at 45-70 kDa. These observations were further confirmed by the analysis of intensities for the prominent bands for each experimental group, using ImageJ Software (Fig 1e). Data is from means of triplicates \pm SD using Mann-Whitney $U$ test for two independent samples of each $25 \mathrm{kDa}, 43 \mathrm{kDa}$, and 30-43 $\mathrm{kDa}^{*}$ and $68 \mathrm{kDa}$ bands. Significant differences between the wild-type and TNF- $\alpha$ transgenic mouse groups; and between the sham-infected and P. gingivalis-infected groups were identified, respectively (Fig. 1e).

\section{Immunohistochemical analysis}

The three different types of negative controls employed remained negative for protein carbonyl immunostain detection. These were (1) where 2,4-DNPH derivatization was omitted (Fig. 2a), (2) where free carbonyl groups were reduced with $25 \mathrm{mM}$ sodium borohydride in $80 \%$ methanol, at room temperature for 30 min, before 2,4-DNPH derivatization (Fig. 2b); and (3) where the primary antibody was excluded (Fig. 2c). Immunostaining of protein carbonyl content within the hippocampus and microvessels of wild-type and TNF- $\alpha$ transgenic mouse brains was similar to that seen in negative controls (Fig. $2 \mathrm{~d}-\mathrm{e}$ ), as was the case with the sham-infected mice (Fig. 2f). However, in $P$. gingivalis-infected mouse brains, protein carbonyl immunostaining was distinctly observed in the vasculature, especially localized within the hippocampal capillaries (Fig. 2g). At higher magnification, the protein carbonyl immunostaining was more distinctly

observed in the microvasculature (boxed areas in Fig. $2 \mathrm{~g}$ are shown at higher magnification in Fig. 2h-i). The microvessels adjacent to the pyramidal neurons of the CA sectors in the hippocampus (Fig. 2j, box), also showed immunostaining localised to the capillaries and endothelial cells (Fig. 2k-1, endothelial cell staining is indicated with arrows).

The frontal brains of wild-type mice demonstrated protein carbonyl immunostaining, but was much weaker at the optimal antibody dilution used (Fig. 3a-b), whereas the TNF- $\alpha$ transgenic mouse tissues exhibited weaker staining of the myelin bundles (Fig. 3c) and occasional cellular staining (Fig. 3c-d). The 
sham-infected mouse tissue sections demonstrated marked staining of the myelin sheath regions (Fig. 3e) and neuronal staining (Fig. 3f). The $P$. gingivalis-infected mouse tissue sections also demonstrated staining of the myelin sheath (Fig. 3g) and neurons (Fig. 3h), whilst certain pyramidal neurons appeared to be completely damaged (Fig. 3h, insert).

\section{Discussion}

As atherosclerosis, strokes and AD share a common APOE4 genetic susceptibility, many investigators have used the $\mathrm{ApoE}^{-/-}$mice as an animal model to assess the influences of co-morbidities of these diseases, including $P$. gingivalis-mediated infection $[32,34,35,38,39]$. In addition, proinflammatory cytokines, such as TNF- $\alpha$, IL-1 $\beta$ and IL-6, are relvant to early stages of AD onset [40]. From animal models, proinflammatory cytokines, such as TNF- $\alpha$, are known to disturb inter-endothelial cell-cell connections and thereby cause BBB permeability [19]. This makes TNF- $\alpha$ transgenic mice [31] and ApoE ${ }^{-/-}$mice brains [27, $29,30]$, ideal test models to investigate if they share common oxidative stress from an intrinsic biological (proinflammatory cytokine) stressor. We first established that the leaky BBB was restricted to the cerebellum and not the cerebral microvessels in both TNF- $\alpha$ transgenic and $\mathrm{ApoE}^{-/-}$mice brains. We have previously demonstrated $P$. gingivalis hematogenous incursion from gingival epithelium to aortic vascular tissues in $\mathrm{ApoE}^{-/-}$mice [35], and into the brain tissues [32, 34]. In adition, innate immune response stimulation was demonstrated by glia via the local synthesis and release of complement cascade proteins following $P$. gingivalis infection of the brain [34]. The activated complement cascade for non-specific lysing of microbes instead, led to an inappropriate attack of pyramidal neurons [34]; and also resulted in accelerated occurrence of age-related granules [32]. Upon entry into the brain following 24 weeks of chronic infection, $P$. gingivalis infection appeared to be contributing towards hippocampal cerebral tissue injury in which impairment of the BBB was evident. This suggested a preceding negative event was taking place and was contributing to the $\mathrm{BBB}$ defect in the infected group. To delinate overlapping cytokine related biological events during infection, inclusion of TNF- $\alpha$ transgenic mice was essential. The rationale for the initiation of the present study was, therefore, to determine if vascular exposure to $P$. gingivalis and/or the 
host's acute phase responses in the form of oxidative stress and corresponding oxidative protein damage, were responsible for the development of a leaky $\mathrm{BBB}$ in $\mathrm{ApoE}^{-/-}$mice at an earlier timepoint of infection (12 weeks), which was not detected at the 24 week infection timepoint. Numerous AD studies have identified the accumulation of carbonylated proteins as a consequence of elevated oxidative stress [41-44]. There are no studies at present that have attempted to address whether the resulting oxidative stress exposure from the invasion of microbes can lead to the development of leaky BBB. Therefore, to the best of our knowledge, this is the first study that has evaluated the putative role of $P$. gingivalis infection in mediating BBB deterioration and its contribution to oxidative protein damage in the $\mathrm{ApoE}^{-/-}$mouse brain model, following bacterial infection.

It is interesting to note that the extent of oxidative protein damage was evident in the wild-type mouse brain tissue lysates, as a prominent band of $43 \mathrm{kDa}$. This data suggests that even wild-type mice experience intrinsic exposure to basal levels of ROS, due to by-products of normal physiological and metabolic processes. This led to the notion that the gradual accumulation of oxidative stress-related proteins was possible in these mice, as antioxidative and repair mechanisms are not being completely (100\%) efficient [45-49]. Although the extent of oxidative protein damage from the frontal lobe brain region in wildtype mice was detectable by Western blotting, this was largely restricted to a single band at $43 \mathrm{kDa}$. The Western blot profiles for the TNF- $\alpha$ transgenic mice differed to those of wild-type mice, particularly by demonstrating enhanced carbonylated proteins at around $25 \mathrm{kDa}, 43 \mathrm{kDa}$ and $68 \mathrm{kDa}$. This difference may be attributable to the endogenous expression of proinflammatory cytokine and an impaired cerebellar BBB as a consequence of enhanced oxidative stress. Therefore, the endogenous antioxidant and repair systems within the brains of TNF- $\alpha$ transgenic mice were incapable of overcoming the corresponding increases in oxidative stress caused by the enhanced proinflammatory cytokine burden, resulting in increased protein carbonylation and host tissue damage. Differences in Western blot profiles were further evident between the sham-infected mice and those infected with $P$. gingivalis at similar age. $P$. gingivalis-infected mice demonstrated the highest overall protein carbonyl content among all of the experimental groups analysed, with numerous prominent bands identified at $25 \mathrm{kDa}$ and $30-43 \mathrm{kDa}^{*}$ (exclusive to the infected group) and 
at $43 \mathrm{kDa}$, with lesser intensity bands at 45-70 $\mathrm{kDa}$. In contrast, sham-infected mice only demonstrated a prominent band at around $25 \mathrm{kDa}$, with additional bands of highly variable degrees of intensitites between 29-40 $\mathrm{kDa}$ and 45-70 $\mathrm{kDa}$. In addition, these observations are consistent with previous reports that have shown $P$. gingivalis can not only survive host's oxidative burst, but also has the ability to subvert its own oxidative stress via rubreythrin gene activation [12]. ApoE $\mathrm{E}^{-/-}$mice are also predisposed to intrinsic stress due to constitutive TNF- $\alpha$ expression [21, 22], oxidative stress-induction, lipid peroxidation [23], impaired immuno-modulatory function in macrophages and innate/adaptive immune responses [24-26]; and an impaired cerebellar BBB [27]. Thus, the prominent band at around $25 \mathrm{kDa}$, common to TNF- $\alpha$ transgenic mice, sham- and P. gingivalis-infection blots from $\mathrm{ApoE}^{-/-}$mice, reflects the shared oxidative stress as a consequence of the constitutive expression of TNF- $\alpha$ and cerebellar BBB defects. However, the increased acute phase inflammatory response, as shown by detectable oxidative protein content in $P$. gingivalis mouse brains, particularly at 30-43 $\mathrm{kDa}^{*}$, are more a consequence of infection. Accordingly, this study supports the host's phagocytic cell oxidative burst initated by $P$. gingivalis infection/pathogenicity to initiate and perpetuate BBB damage [12].

In line with Western blot data, immunohistochemical detection of protein carbonyl content in the tissue sections taken from the frontotemporal lobe inclusive of the hippocampus, only low to negligible levels were consistently seen among the wild-type and TNF- $\alpha$ transgenic mice brains. This suggested that these mice were exposed to oxidative stress, but that was below the threshold of detection by immunohistochemistry at the optimal dilution of the primary antibody tested. TNF- $\alpha$ transgenic mouse brain tissue sections showed infrequent immunostaining on myelinated nerve bundles and occasional cellular sites, particularly in non-hippocampal areas of the brain. These findings suggest certain strain and age similarities, but equally imply the existence of differences in the levels and responses to oxidative stress within these anatomical regions of the brain in the TNF- $\alpha$ transgenic mice. As these mice are associated with a persistent low-grade exposure to TNF- $\alpha$, this alters antioxidant defences and perpetuates oxidative stress and tissue damage within these mice $[50,51]$. Therefore, the detection of increased protein carbonyl levels in these mice is expected, as these mice appear to be less efficient in counteracting the elevated levels of 
oxidative stress induced by TNF- $\alpha$ and the cerebellar BBB defect. In addition, live $P$. gingivalis infection is likely to exert its effect on the host through other virulence factors, such as its proteolytic activity mediated by gingipains [13-15]. Concerning the microvascular structure of the brain, it is plausible to extrapolate relevant information from cell-cell junctional protein (catenins, occludin, E-cadherin and $\beta_{1}$-integrin) disruption from in vitro infection data already documented [13-15]. Therefore, endothelial tight junction protein disruption by this periodontal pathogen to facilitate self-accessibility across the BBB is highly plausible and confirms IgG leakage into the microvasculature at later timepoints of infection [32].

It is clear that both sham- and $P$. gingivalis-infection of $\mathrm{ApoE}^{-/-}$mice at 12 weeks exhibited significant detectable protein carbonyl content by Western blotting, but immunohistochemistry showed the major difference in its staining pattern, which was the microvasculature in the hippocampus region of the brain. This observation confirms that $P$. gingivalis infection plays a significant role in increasing the hosts' oxidative stress, which subsequently has a significant pathological impact on the cerebral microvasculature. It is reported that the cerebral $\mathrm{BBB}$ is breached among the elderly humans and AD subjects [52], but the reasons behind it are poorly understood. One plausible reason is that the episodic nature of periodontal disease, in which patients experience recurrent periods of quiesscense and active disease. The biofilm bacteria of the active (recurring) phase of periodontitis are likely to be those that have been newly 'radicalised' as suggested by Harding et al., [53] to possess greater inflammophilic virulent properties. It is highly possible that these cyclic exposures of $P$. gingivalis infections together with its 'radicalised' companion species occur during recurrent bacteremias [54], which could contribute to eventual loss of cerebral BBB integrity and function.

These findings imply that $P$. gingivalis infection significantly increases the overall oxidative stress within the brains of $\mathrm{ApoE}^{-/-}$mice, resulting in enhanced cellular and molecular damage, culminating in an accumulation of protein carbonyl content. $P$. gingivalis is a well-established mediator of infection and hostderived, tissue damage during periodontitis, where similar to $\mathrm{AD}$, oxidative stress has been implicated in the pathogenesis of disease [1-7]. Indeed, $P$. gingivalis levels have been shown to correlate with oxidative stress biomarker levels during periodontal disease and other inflammatory diseases such as atherosclerosis, where 
this bacterium has been implicated $[55,56]$. Therefore, the present findings suggest that P. gingivalis infection is capable of inducing significant immuno-inflammatory responses and associated oxidative stress in the hippocampi of $\mathrm{ApoE}^{-/-}$mice, which is characteristically prominent in the microvascular regions.

In conclusion, this study has revealed a major difference in the hippocampi of $P$. gingivalis-infected and sham-infected $\mathrm{ApoE}^{-/-}$mice, in terms of increased protein carbonyl/oxidized protein content in the hippocampal micro-vasculature. We, therefore, suggest that hippocampal microvascular structures and the homeostasis of the brain are at risk from elevated oxidative stress and oxidative protein damage, following $P$. gingivalis infection. This observation has significant implications as it suggests that following recurrent episodes of active periodontal disease there exists a possibility for the development of a defective BBB, post neuroinflammation-mediated cerebral parenchymal tissue injury. It is, therefore, highly plausible that the rising levels of intrinsic and extrinsic sources of cytokines, oxidative stress and developing BBB defects are crucial early modifiers of neurodegeneration and disease severity leading to deteriorating memory. Thus, infection with $P$. gingivalis should be interpreted as one of the plausible mechanisms by which a susceptible host can develop dementia.

\section{Acknowledgements}

All authors have no conflict of interest to declare. The authors thank the financial support from NIH/NIDCR 1R01 DE020820-01A1 awarded to LK. The research work undertaken in this manuscript was fully funded by the University of Central Lancashire, UK. SKS would like to thank the Undergraduate Internship Scheme during 2015-2016 which were also fully funded by the University of Central Lancashire. The authors acknowledge the help of Miss Anya F. Snary who carried out preliminary testing of the methodology as part of the 2016 Internship. We would like to thank Professor George Kollias (Biomedical Sciences Research Center "Alexander Fleming", Athens, Greece), for providing the Tg197 TNF-Tg (TNF- $\alpha$ ), mice. The Biomedical Services Unit (University of Birmingham) for supporting animal experiments and the Department of Musculoskeletal Pathology (Robert Aitken Institute, University of Birmingham) for 
embedding and cutting tissues for histology. This work was supported by Arthritis Research UK grants (References: 19859 and 20843). 


\section{References}

[1] Waddington RJ, Moseley R, Embery G (2000) Reactive oxygen species: A potential role in the pathogenesis of periodontal diseases. Oral Dis 6, 138-151.

[2] Chapple IL, Matthews JB (2007) The role of reactive oxygen and antioxidant species in periodontal tissue destruction. Periodontol 2000 43, 160-232.

[3] Guo C, Sun L, Chen X, Zhang D (2013) Oxidative stress, mitochondrial damage and neurodegenerative diseases. Neural Regen Res 8, 2003-2014.

[4] Radi E, Formichi P, Battisti C, Federico A (2014) Apoptosis and oxidative stress in neurodegenerative diseases. J Alzheimers Dis 42, S125-S152.

[5] Cobb CA, Cole MP (2015) Oxidative and nitrative stress in neurodegeneration. Neurobiol Dis 84, 4-21.

[6] Cassano T, Pace L, Bedse G, Lavecchia AM, De Marco F, Gaetani S, Serviddio G (2016) Glutamate and mitochondria: Two prominent players in the oxidative stress-induced neurodegeneration. Curr Alzheimer Res 13, 185-197.

[7] Tramutola A, Lanzillotta C, Perluigi M, Butterfield DA (2016) Oxidative stress, protein modification and Alzheimer disease. Brain Res Bull pii: S0361-9230, 30129-0.

[8] Castellani RJ, Moreira PI, Perry G, Zhu X (2012) The role of iron as a mediator of oxidative stress in Alzheimer's disease. Biofactors 38(2), 133-138.

[9] Wilson DF, Harrison DK, Vinogradov SA (2012) Oxygen, pH and mitochondrial oxidative phosphorylation. J Appl Physiol 113, 1838-1845.

[10] Olsen I, Singhrao SK (2015) Can oral infection be a risk factor for Alzheimer's disease? J Oral Microbiol 7, 29143.

[11] Roberts FA, Richardson GJ, Michalek SM 1(997) Effects of Porphyromonas gingivalis and Escherichia coli lipopolysaccharides on mononuclear phagocytes. Infect Immun 65(8), 3248-3254.

[12] Mydel P, Takahashi Y, Yumoto H, Sztukowska M, Kubica M, Gibson FC $3^{\text {rd }}$, Kurtz DM jr, Travis J, Collins LV, Nguyen KA, Genco CA, Potempa J (2006) Roles of the host oxidative immune response and bacterial antioxidant ruberythrin during Porphyromonas gingivalis infection. PLoS Pathog 2, e76. 
[13] Katz J, Sambandam V, Wu JH, Michalek SM, Balkovetz DF (2000) Characterization of Porphyromonas gingivalis-induced degradation of epithelial cell junctional complexes. Infect Immun 68, $1441-1449$.

[14] Hintermann E, Haake SK, Christen U, Sharabi A, Quaranta V (2002) Discrete proteolysis of focal contact and adherens junction components in Porphyromonas gingivalis-infected oral keratinocytes: a strategy for cell adhesion and migration disabling. Infect Immun 70(10), 5846-5856.

[15] Sheets SM, Potempa J, Travis J, Casiano CA, Fletcher HM (2005) Gingipains from Porphyromonas gingivalis W83 induce cell adhesion molecule cleavage and apoptosis in endothelial cells. Infect Immun 73(3), 1543-1552.

[16] Tamagno E, Guglielmotto M, Aragno M, Borghi R, Autelli R, Giliberto L, Muraca G, Danni O, Zhu X, Smith MA, Perry G, Jo DG, Mattson MP, Tabaton M (2008) Oxidative stress activates a positive feedback between the $\gamma$ - and $\beta$-secretase cleavages of the $\beta$-amyloid precursor protein. $J$ Neurochem 104, 683-695.

[17] Singhal G, Jaehne EJ, Corrigan F, Toben C, Baune BT (2014) Inflammasomes in neuroinflammation and changes in brain function: A focused review. Front Neurosci $\mathbf{8}, 315$.

[18] Olsen I, Singhrao SK (2016) Inflammasome involvement in Alzheimer's disease. J Alzheimers Dis 54, 45-53.

[19] Lv S, Song HL, Zhou Y, Li LX, Cui W, Wang W, Liu P (2010) Tumour necrosis factor-alpha affects blood-brain barrier permeability and tight junction-associated occludin in acute liver failure. Liver Int 30, $1198-1210$.

[20] Basuroy S, Bhattacharya S, Tcheranova D, Qu Y, Regan RF, Leffler CW, Parenova H (2006) HO-2 provides endogenous protection against oxidative stress and apoptosis caused by TNF-alpha in cerebral vascular endothelial cells. Am J Physiol Cell Physiol 291, C897-C908.

[21] Roselaar SE, Daugherty A (1998) Apolipoprotein E-deficient mice have impaired innate immune responses to Listeria monocytogenes in vivo. J Lipid Res 39, 1740-1743. 
[22] de Bont N, Netea MG, Demacker PN, Verschueren I, Kullberg BJ, van Dijk KW, van der Meer JW, Stalenhoef AF (1999) Apolipoprotein E knock-out mice are highly susceptible to endotoxemia and Klebsiella pneumoniae infection. J Lipid Res 40, 680-685.

[23] Ramassamy C, Krzywkowski P, Averill D, Lussier-Cacan S, Theroux L, Christen Y, Davignon J, Poirier J (2001) Impact of apoE deficiency on oxidative insults and antioxidant levels in the brain. Brain Res Mol Brain Res 86, 76-83.

[24] Ophir G, Amariglio N, Jacob-Hirsch J, Elkon R, Rechavi G, Michaelson DM (2005) Apolipoprotein E4 enhances brain inflammation by modulation of the NF-אB signaling cascade. Neurobiol Dis 20, 709718.

[25] Tsoi LM, Wong KY, Liu YM, Ho YY (2007) Apoprotein E isoform-dependent expression and secretion of pro-inflammatory cytokines TNF- $\alpha$ and IL-6 in macrophages. Arch Biochem Biophys 460, $33-40$.

[26] Vitek MP, Brown CM, Colton CA (2009) APOE genotype-specific differences in the innate immune system. Neurobiol Aging 30,1350-1360.

[27] Fullerton SM, Shirman GA, Strittmatter WJ, Matthew WD (2001) Impairment of the blood-nerve and blood-brain barriers in apolipoprotein e knockout mice. Exp Neurol 169, 13-22.

[28] Methia N, André P, Hafezi-Moghadam A, Economopoulos M, Thomas KL, Wagner DD (2001) ApoE deficiency compromises the blood brain barrier especially after injury. Mol Med 7, 810-815.

[29] Mulder M, Blokland A, van den Berg DJ, Schulten H, Bakker AH, Terwel D, Honig W, de Kloet ER, Havekes LM, Steinbusch HW, de Lange EC (2001) Apolipoprotein E protects against neuropathology induced by a high-fat diet and maintains the integrity of the blood-brain barrier during aging. Lab Invest 81, 953-960.

[30] Hafezi-Moghadam A, Thomas KL, Wagner DD (2007) ApoE deficiency leads to a progressive agedependent blood-brain barrier leakage. Am J Physiol Cell Physiol 292, C1256-C1262. 
[31] Keffer J, Probert L, Cazlaris H, Georgopoulos S, Kaslaris E, Kioussis D, Kollias G (1991) Transgenic mice expressing human tumour necrosis factor: A predictive genetic model of arthritis. EMBO $J \mathbf{1 0}$, 4025-4031.

[32] Singhrao SK, Chukkapalli S, Poole S, Velsko I, Crean S, Kesavalu L (2017) Chronic Porphyromonas gingivalis infection accelerates the occurrence of age-related granules in $\mathrm{ApoE}^{-/-}$mice brains. J Oral Microbiol 9:1, 1270602.

[33] Poole S, Singhrao SK, Kesavalu L, Curtis MA, Crean S (2013) Determining the presence of periodontopathic virulence factors in short-term postmortem Alzheimer's disease brain tissue. $J$ Alzheimers Dis 36, 665-77.

[34] Poole S, Singhrao SK, Chukkapalli S, Rivera M, Velsko I, Kesavalu L, Crean S (2015) Active invasion of Porphyromonas gingivalis and infection-induced complement activation in ApoE-/- mice brains. $J$ Alzheimers Dis 43, 67-80.

[35] Velsko IM, Chukkapalli SS, Rivera MF, Lee J-Y, Chen H, Zheng D, Bhattacharyya I, Gangula PR, Lucas AR, Kesavalu L (2014) Active invasion of oral and aortic tissues by Porphyromonas gingivalis in mice causally links periodontitis and atherosclerosis. PLOS One 9, e97811.

[36] Moseley R, Hilton JR, Waddington RJ, Harding KG, Stephens P, Thomas DW (2004) Comparison of oxidative stress biomarker profiles between acute and chronic wound environments. Wound Rep Regen 12, 419-429.

[37] Waddington RJ, Alraies A, Colombo JS, Sloan AJ, Okazaki J, Moseley R (2011) Characterization of oxidative stress status during diabetic bone healing. Cells Tiss Organs 194, 307-312.

[38] Lalla E, Lamster IB, Hofmann MA, Bucciarelli L, Jerud AP, Tucker S, Lu Y, Papapanou PN, Schmidt AM (2003) Oral infection with a periodontal pathogen accelerates early atherosclerosis in apolipoprotein E-null mice. Arterioscler Thromb Vasc Biol 23, 1405-1411.

[39] Hayashi C, Viereck J, Hua N, Phinikaridou A, Madrigal AG, Gibson III FC, Hamilton JA, Genco CA (2011) Porphyromonas gingivalis accelerates inflammatory atherosclerosis in the innominate artery of ApoE deficient mice. Atherosclerosis 215, 52-59. 
[40] Sudduth TL, Schmitt FA, Nelson PT, Wilcock DM (2013) Neuroinflammatory phenotype in early Alzheimer's disease. Neurobiol Aging 34, 1051-1059.

[41] Greilberger J, Koidl C, Greilberger M, Lamprecht M, Schroecksnadel K, Leblhuber F, Fuchs D, Oettl K (2008) Malondialdehyde, carbonyl proteins and albumin-disulphide as useful oxidative markers in mild cognitive impairment and Alzheimer's disease. Free Radic Res 42, 633-638.

[42] Shen L, Chen C, Yang A, Chen Y, Liu Q, Ni J (2015) Redox proteomics identification of specifically carbonylated proteins in the hippocampi of triple transgenic Alzheimer's disease mice at its earliest pathological stage. J Proteomics 123, 101-113.

[43] Rommer PS, Fuchs D, Leblhuber F, Schroth R, Greilberger M, Tafeit E, Greilberger J (2016) Lowered levels of carbonyl proteins after vitamin B supplementation in patients with mild cognitive impairment and Alzheimer's disease. Neurodegener Dis 16, 284-289.

[44] Shen L, Chen Y, Yang A, Chen C, Liao L, Li S, Ying M, Tian J, Liu Q, Ni J (2016) Redox proteomic profiling of specifically carbonylated proteins in the serum of triple transgenic Alzheimer's disease mice. Int J Mol Sci 17, 469.

[45] Sohal RS (2002) Role of oxidative stress and protein oxidation in the aging process. Free Radic Biol Med 33, 37-44.

[46] Sohal RS, Mockett RJ, Orr WC (2002) Mechanisms of aging: An appraisal of the oxidative stress hypothesis. Free Radic Biol Med 33, 575-586.

[47] Sung S, Yao Y, Uryu K, Yang H, Lee VM, Trojanowski JQ, Praticò D (2004) Early vitamin E supplementation in young but not aged mice reduces Abeta levels and amyloid deposition in a transgenic model of Alzheimer's disease. FASEB J 18, 323-325.

[48] Lee HP, Pancholi N, Esposito L, Previll LA, Wang X, Zhu X, Smith MA, Lee HG (2012) Early induction of oxidative stress in mouse model of Alzheimer disease with reduced mitochondrial superoxide dismutase activity. PLoS One 7, e28033. 
[49] Mota SI, Costa RO, Ferreira IL, Santana I, Caldeira GL, Padovano C, Fonseca AC, Baldeiras I, Cunha C, Letra L, Oliveira CR, Pereira CM, Rego AC (2015) Oxidative stress involving changes in Nrf2 and ER stress in early stages of Alzheimer's disease. Biochim Biophys Acta 1852, 1428-1441.

[50] Li X, Moody MR, Engel D, Walker S, Clubb FJ Jr, Sivasubramanian N, Mann DL, Reid MB (2000) Cardiac-specific overexpression of tumour necrosis factor- $\alpha$ causes oxidative stress and contractile dysfunction in mouse diaphragm. Circulation 102, 1690-1696.

[51] Glosli H, Tronstad KJ, Wergedal H, Müller F, Svardal A, Aukrust P, Berge RK, Prydz H (2002) Human TNF- $\alpha$ in transgenic mice induces differential changes in redox status and glutathioneregulating enzymes. FASEB $J \mathbf{1 6}, 1450-1452$.

[52] Montagne A, Barnes SR, Sweeney MD, Halliday MR, Sagare AP, Zhao Z, Toga AW, Jacobs RE, Liu CY, Amezcua L, Harrington MG, Chui HC, Law M, Zlokovic BV (2015) Blood-brain barrier breakdown in the aging human hippocampus. Neuron 85, 296-302.

[53] Harding A, Robinson S, Crean S, Singhrao SK (2017) Can better management of periodontal disease delay the onset and progression of Alzheimer's disease? J Alzheimers Dis 58, 337-348.

[54] Forner L, Larsen T, Kilian M, Holmstrup P (2006) Incidence of bacteremia after chewing, tooth brushing, and scaling in individuals with periodontal inflammation. J Clin Periodontol 33, 401-407.

[55] Sawamoto Y, Sugano N, Tanaka H, Ito K (2005) Detection of periodontopathic bacteria and an oxidative stress marker in saliva from periodontitis patients. Oral Microbiol Immunol 20, 216-220.

[56] Kurita-Ochiai T, Yamamoto M (2014) Periodontal pathogens and atherosclerosis: Implications of inflammation and oxidative modification of LDL. Biomed Res Int 595981. 
Figures and Legends

Figure 1

a

WT mice brains

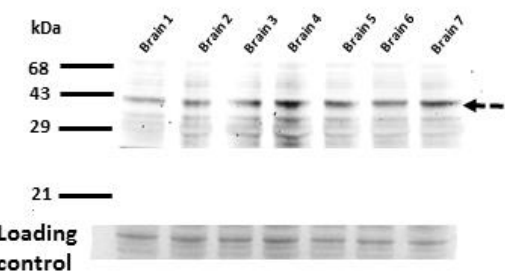

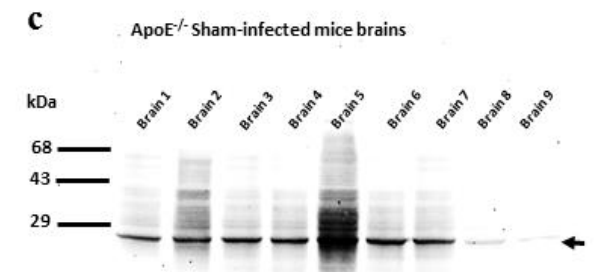

${ }^{21}$

Loading control b

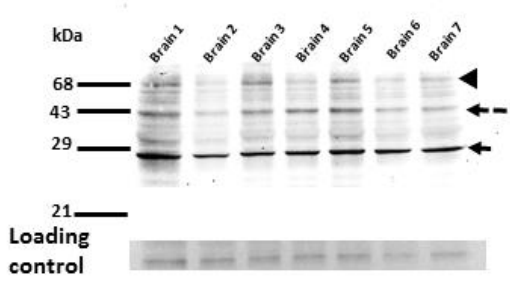

d

ApoE- - P. gingivalis infected

b TNF- $\alpha$ Tg mice brains

$\mathrm{kDa}$ 68 -

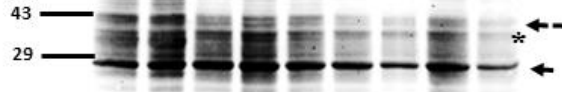
$\underset{\text { Loading }}{21} \equiv \equiv \equiv \equiv \equiv$

Figure 1e

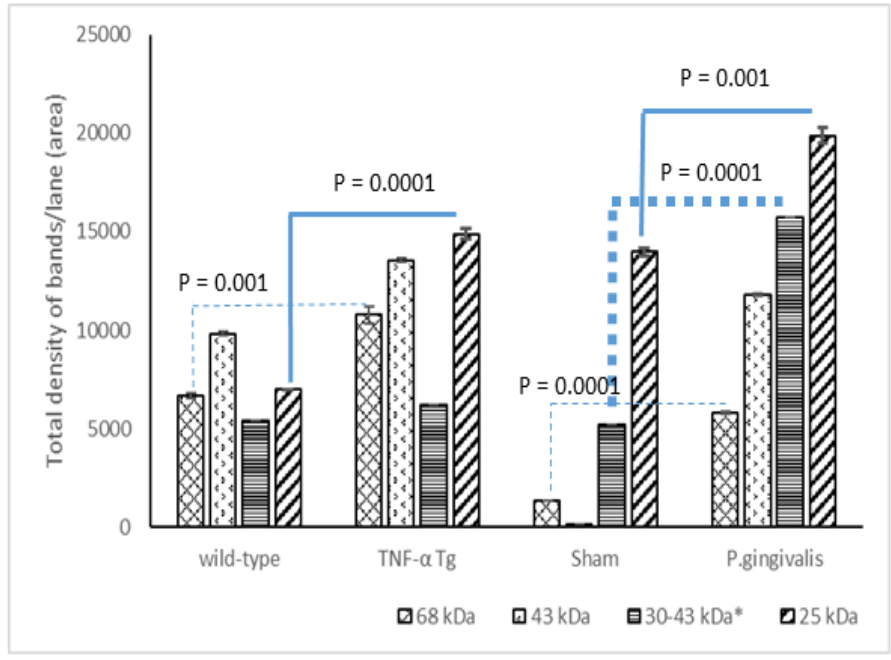




\section{Figure 1}

Representative OxyBlot profiles demonstrating protein carbonyl band intensities in wild-type (a), TNF- $\alpha$ transgenic (b), sham-infected (c), and P. gingivalis-infected (d) mouse brain lysates. All samples demonstrated protein carbonyl content and the presence of multiple oxidised proteins. Differences in the mean band intensities of the prominent bands at around $25 \mathrm{kDa} 43 \mathrm{kDa}, 30-43 \mathrm{kDa}^{*}$ and $68 \mathrm{kDa}$ between each group using Image J Software (3 replicate blots analysed). Non-parametric Mann-Whitney U (e) Shows normalised data from mean of means of triplicates \pm SD. Significance indicated (see $p$ values in Fig. 1e) in protein carbonyl and oxidative stress levels between wild-type and TNF- $\alpha$ transgenic mice and the shaminfected and $P$. gingivalis-infected mice. 
Figure 2

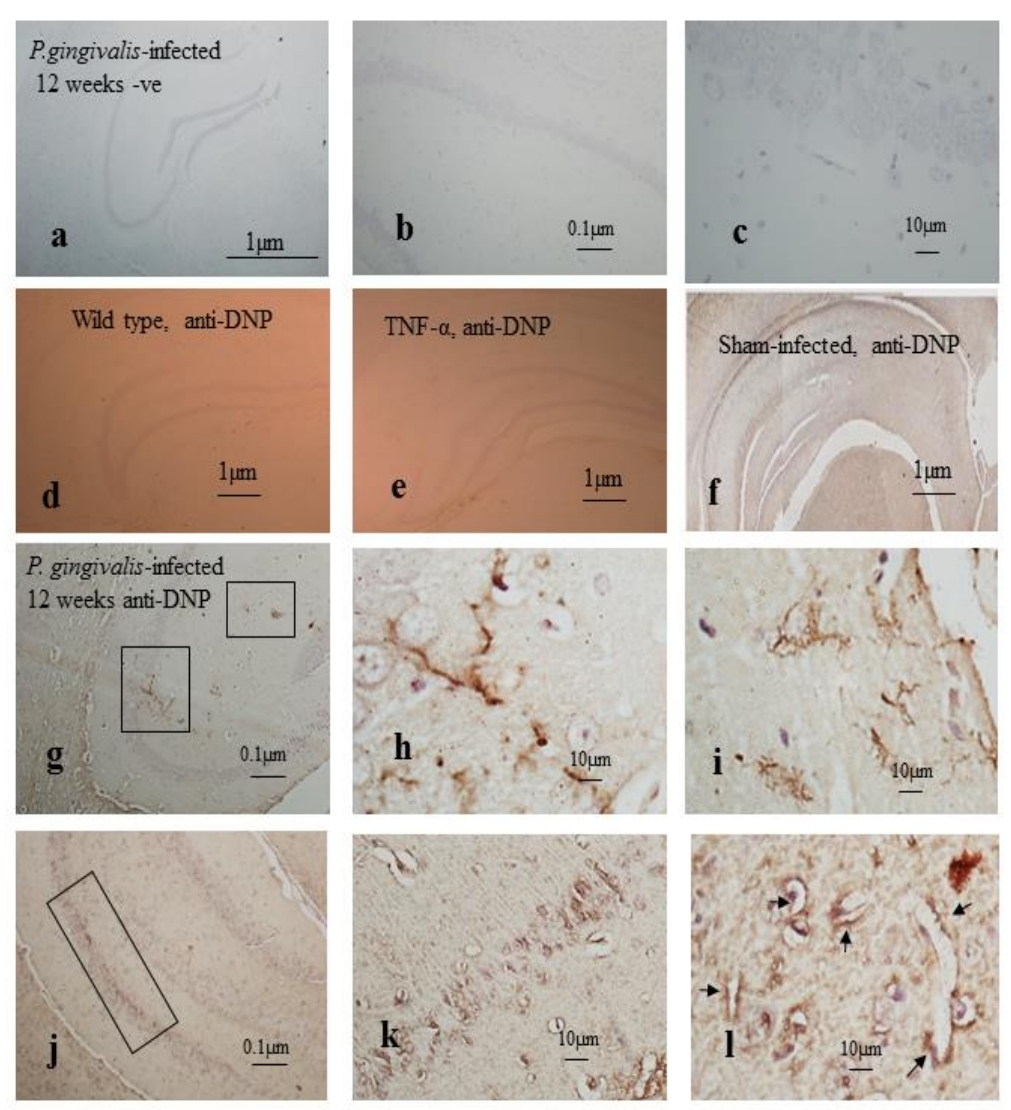

\section{Figure 2}

Compared with the controls (2a-c), immunohistochemical detection of protein carbonyl groups within wild-type brains and TNF- $\alpha$ transgenic mouse hippocampi generally demonstrated lower protein carbonyl immunostaining overall or within the microvessels $(2 \mathrm{~d}-\mathrm{e})$. This was also the case in sham-infected mouse hippocampi, although staining was observed within the pyramidal neurons (2f). $P$. gingivalis-infected mouse brains exhibited protein carbonyl immuno-staining in the vasculature, especially localized within the hippocampal capillaries (2g). The boxed areas in Fig. $2 \mathrm{~g}$ are shown at higher magnification (2h, i), to further demonstrate the microvasculature. The capillaries adjacent to the CA neurons of the hippocampus (2j, box) also showed immuno-staining localised to the capillaries and endothelial cells (2k-1, arrows denote endothelial cell staining). 


\section{Figure 3}

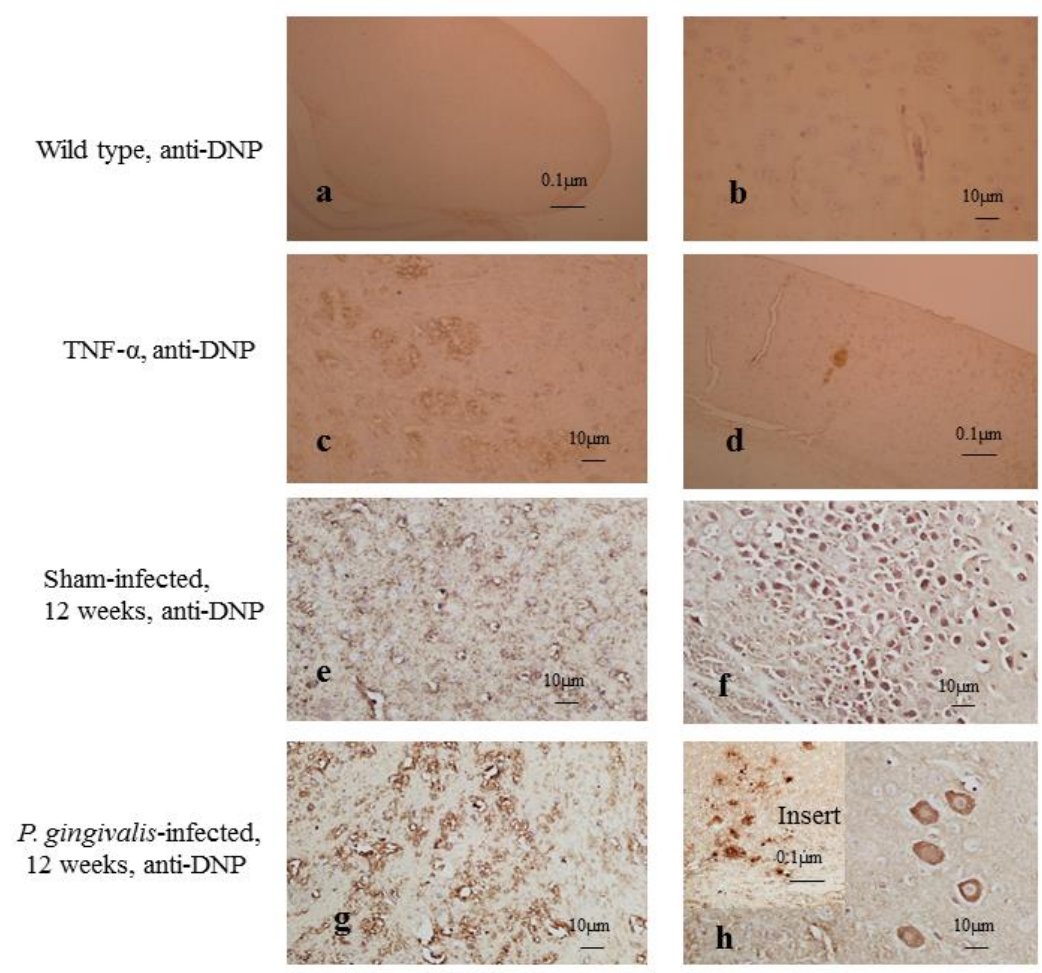

\section{Figure 3}

Immunohistochemical detection of protein carbonyl groups within the thalamus (3a) and frontal lobe (3b) of wild-type mice generally showed little immuno-staining, whereas TNF- $\alpha$ transgenic mice frontal brains demonstrated weak straining on myelin bundles (3c) and occasional cellular staining (3d). Sham-infected mice tissue sections demonstrated marked staining of the myelin sheath regions (3e) and neuronal staining (3f). P. gingivalis-infected mouse tissue sections also demonstrated staining of the myelin sheath (3g) and neurons (3h), whilst certain neurons appeared to be completely damaged (3h, insert). 